\section{UC Malaria Research and Control Group vows to defeat malaria}

Twenty-one scientists from five UC campuses are partnering with the Mosquito and Vector Control Association of California to defeat one of the world's oldest and deadliest diseases: malaria.

Malaria infects some 350 to 500 million people a year, killing between 1 million and 2.5 million, according to the World Health Organization. Ninety percent of the global incidence of malaria occurs in Africa, where a child dies from the disease every 30 seconds.

The UC Malaria Research and Control Group (MRCG) vows to change that. The group, formed in February 2006, is a branch of the UC Mosquito Research Program, a statewide program of the UC Division of Agriculture and Natural Resources.

"We're firmly committed to defeating the most formidable and challenging mosquito-borne dis- ease," says medical entomologist and MRCG director Gregory Lanzaro, who also directs the UC Mosquito Research Program and the UC Davis Center for Vectorborne Diseases.

"This is all about saving lives," Lanzaro says. "It's the right thing to do. We are combining compassion, technology and science to defeat a killer."

Malaria, first recognized 4,000 years ago and eradicated in the United States in the early 1950s, has been eliminated in many parts of Asia, Europe and the Americas, but is raging uncontrolled in many parts of Africa, Lanzaro says. "The spike can be attributed to more efficient mosquito vectors, increased pesticide and drug resistance, and socioeconomic factors, including struggling health systems."

Malaria threatens more than 100 countries and territories, with more than $40 \%$ of the world's population at risk, according to the U.S. Centers for Disease Control and Prevention. Children under age 5 and pregnant women are most susceptible.

\title{
UC Davis scientist recounts battle with neuroinvasive West Nile virus
}

\section{Keira Simmons knew something was wrong the minute she woke up that fateful morning in mid-June 2005.}

A strange red rash splotched her inner arms and torso. Within 4 days, the rash covered her entire body, even between her fingers and toes. A knife-splitting headache, coupled with crushing muscle pain, vomiting, neck stiffness, fatigue, dizziness and nausea ensued.

Her normal $98.5^{\circ} \mathrm{F}$ degree temperature spiked to $102^{\circ} \mathrm{F}$ and then raged to $106.5^{\circ} \mathrm{F}$. She dropped 20 pounds in 10 days.

The UC Davis scientist remembers four trips to the hospital emergency room, a 3-day hospitalization to treat the raging fever, worsening pain, dizziness and dehydration, and a 3-week recovery period at home. The illness incapacitated her for 7 weeks.

It nearly killed her.

"The doctors thought I had the flu," recalls Simmons, then 27 and a postgraduate researcher in a UC Davis School of Medicine lab.

It was not the flu.

For more information:

Symptoms of West Nile virus www.cdc.gov/ncidod/dvbid/westnile/ qa/symptoms.htm

UC Center for Vectorborne Diseases

http://www.vetmed.ucdavis.edu/cvec
Only after she had accepted a research position in November 2005 at the UC Davis Center for Vectorborne Diseases (known as CVEC), did a routine blood test confirm her worst suspicions: neuroinvasive West Nile virus, the most severe virus spread by Culex mosquitoes.

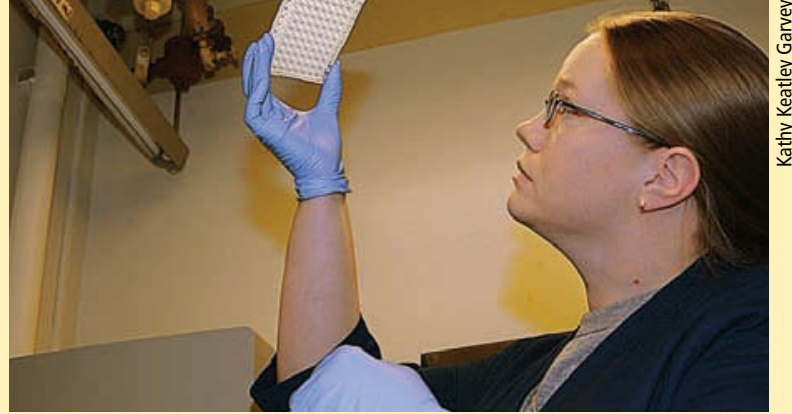

Keira Simmons, now a researcher at the UC Davis Center for Vectorborne Diseases, still suffers side effects from West Nile virus.

"Keira's blood test proved strongly positive for the West Nile virus," said CVEC research entomologist William Reisen, who researches Culex mosquitoes.

Looking back, Simmons speculates that the infected mosquito bit her when she and her fiancé were hiking along Putah Creek on the UC Davis campus.

Hospital technicians drew her blood, but Simmons learned later that it was never tested for West Nile virus, even though she had repeatedly asked for the test. "They ran a few noninvasive tests and some cultures. When none of them was conclusive, they simply gave me IV fluids and sent me home. They said I had the flu."

The illness alarmed her family and friends. "No one around me had been sick and no one was getting sick from exposure to me. It was quite frightening for my 
Lanzaro, who researches Anopheles gambiae, the principal vector of malaria in Africa, says the most deadly parasite is Plasmodium falciparum. It can kill within hours of noticeable symptoms, which include high fever, severe headache, drowsiness, delirium and confusion. The malaria mosquitoes bite at night, usually between 10 p.m. and 4 a.m.

\section{Focus on research and education}

At its organizational meeting in May 2006, MRCG agreed to focus on academic research, education and public service. Its mission is threefold: facilitate collaborative activities, including organized research and training; mitigate the malaria burden in Africa; and provide technical advice to public health agencies on malaria control programs, based

mom, dad, sister and fiancé to stand by, powerless, and watch me deteriorate."

When her personal physician admitted her to the hospital, "I wasn't real aware of my surroundings or what was going on at that time. I had literally started to mentally check out," she says. "I was quite fortunate that I had my fiancé, family and my physician advocating on my behalf."

Today side effects still persist. "I feel generally healthy," Simmons says, "but I still have about three or four headaches of migraine-intensity a week. I also still have some weakness in my arms and hands, affecting my manual dexterity. I have transient spells of vertigo that leave me unable to work in my capacity as a researcher."

"I have no idea when these symptoms will resolve. West Nile virus is so new to our population that they really don't have any idea how it may affect people or their quality of life."

Since her encounter with the infected mosquito, Simmons works with a renewed interest as a researcher and the lead molecular technician at CVEC, testing mosquito pools and dead bird tissue submitted from throughout the state.

Had she not changed jobs and taken the mandatory blood test, Simmons believes the disease may have gone undiagnosed. Her reaction to the positive blood test? "Vindicated. Validated. I knew there was something seriously wrong with me." - Kathy Keatley Garvey

on mosquito abatement in Africa.

Individual members of MRCG are involved in eight African partnerships and two researchtraining grants.

Basic researchers study mosquito molecular genetics, population genomics and the ecology of malaria vectors, mosquito mating biology, and the genetics of immunology and biochemistry of A.gambiae/P. falciparum interactions.

Applied research involves the evaluation of existing insecticide-based control strategies, the development of novel mosquito attractants, new assays for the detection of metabolic insecticide resistance in mosquitoes, the role of agricultural insecticide use in the development of resistance in mosquitoes, the mass-rearing of $A$. gambiae, and models for malaria associated with rice agriculture.

Lanzaro and UC Davis medical entomologist Anthony Cornel of the UC Mosquito Research Laboratory, located at the Kearney Agricultural Center in Parlier, have conducted fieldwork in Africa for more than 15 years, zeroing in on insecticide and drug resistance and population genetics. Last summer, medical entomologist Shirley Luckhart, a UC Davis School of Medicine faculty member, and entomology graduate students Tara Thiemann and Lisa Reimer joined them in Mali. Cornel, a native of South Africa, and Thiemann also worked in Cameroon last summer.

Funded by a National Institutes of Health grant, Lanzaro is researching the complex genetic structure of $A$. gambiae. “Using DNA markers we have been able to demonstrate that subpopulations of this mosquito exist in nature that do not interbreed and therefore do not exchange genes," Lanzaro says. "These subpopulations often exist even within a single village. This has important 


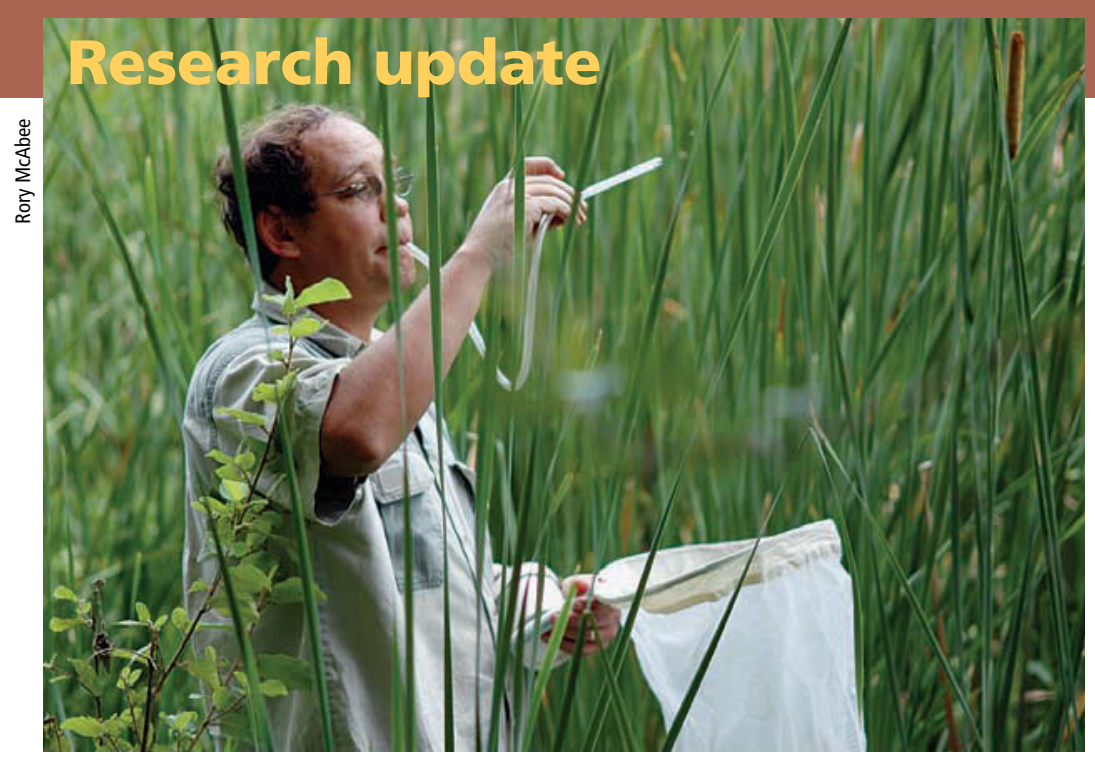

Anthony "Anton" Cornell, UC Davis medical entomologist, collects mosquitoes; one focus of his work is insecticide resistance in malaria vectors.

consequences to understand patterns of resistance to insecticides that form the basis of malaria control campaigns."

Cornel's work focuses on understanding environmental exposures to insecticides and the various mechanisms responsible for mosquito resistance to insecticides. This includes developing field assays to monitor resistance, an important factor in malaria control programs.

Luckhart's research is aimed at understanding the relationship between malaria parasites and their mosquito vectors. "Her work is improving our understanding of why some mosquitoes are capable of transmitting this deadly parasite, while others do not," Lanzaro says.

\section{Delegations to Tanzania, the White House}

A four-member MRCG delegation, led by Lanzaro and Cornel, journeyed to Tanzania in midOctober to develop collaborations and build partnerships for malaria control and research. "Malaria is the leading cause of death in both children and

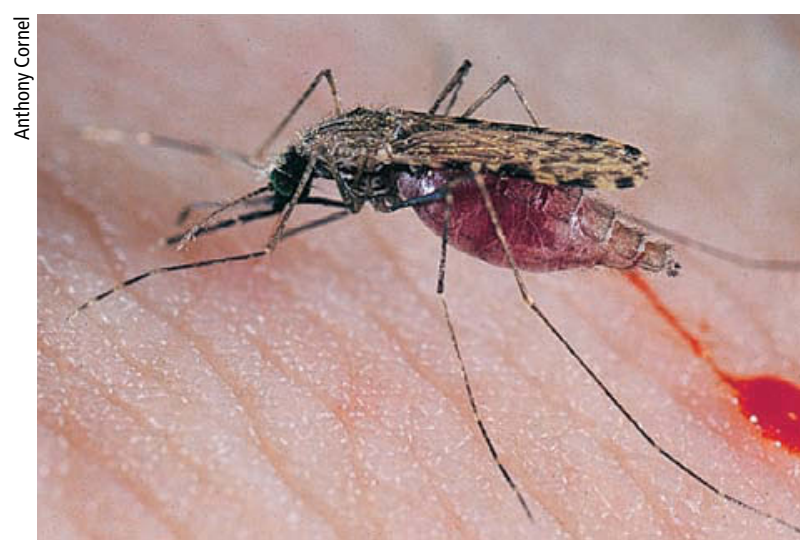

In Africa, the Anopheles gambiae mosquito transmits Plasmodium falciparum, the parasite that causes malaria.

adults in Tanzania," Lanzaro says. "In 2003, the most recent year for which information is available, there were more than 10 million cases of malaria in Tanzania."

The delegation included two representatives from the Mosquito Vector and Control Association of California: Major Dhillon, manager of the Northwest Mosquito and Vector Control District, Corona; and Steve Mulligan, who manages the Consolidated Mosquito Abatement District, Selma.

Lanzaro also represented MRCG at the Dec. 14, 2006, White House Summit on Malaria, which brought together international experts; corporations and foundations; African civic leaders; and voluntary, faith-based and nonprofit organizations. The goal is to raise awareness of malaria and to mobilize a grassroots effort to save millions of lives in Africa. President Bush declared April 25 as Malaria Day.

In response, Lanzaro has organized the firstever Malaria Awareness Day symposium on the UC Davis campus for April 25, gathering members of the scientific community to discuss malaria and the UC Davis commitment to global health. Topics will range from the history of malaria in California to current novel malaria-control strategies in Africa.

Speaking on the history of malaria in California will be Robert K. Washino, professor and chair emeritus of the UC Davis entomology department, and co-author of Mosquitoes of California.

"Malaria," Washino says, "will continue to be of concern to residents of California due to continued travel outside the United States by civilian and military personnel, immigration policies and most recently, the potential effect of global warming on mosquito-parasite interactions involved in malaria transmission." - - Kathy Keatley Garvey

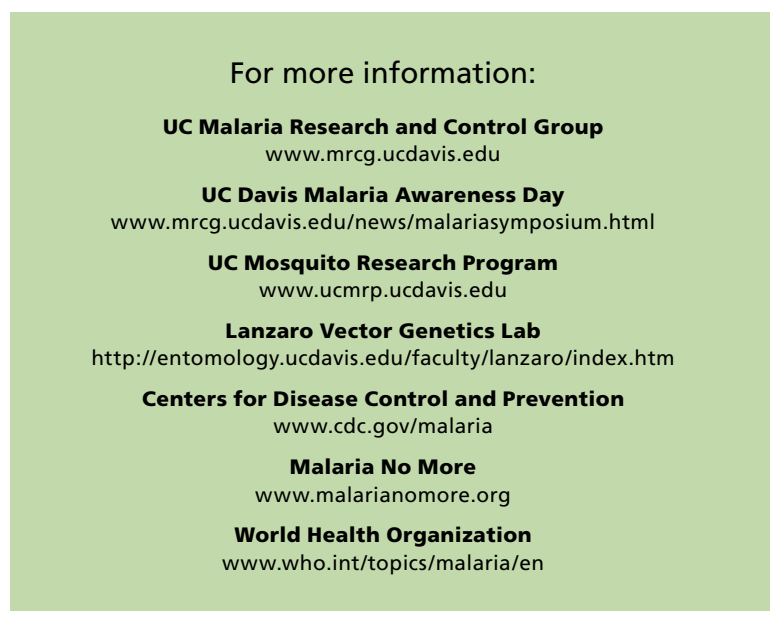

